\title{
microRNA-493 inhibits tongue squamous cell carcinoma oncogenicity via directly targeting HMGA2
}

This article was published in the following Dove Press journal: OncoTargets and Therapy

\author{
Dan Jiao' \\ Yingying $\mathrm{Liu}^{2}$ \\ Zhen $\operatorname{Tian}^{3}$ \\ 'Department of Ultrasound, China-Japan \\ Union Hospital, Jilin University, \\ Changchun 130033, People's Republic of \\ China; ${ }^{2}$ Department of Nephrology, \\ China-Japan Union Hospital, Jilin \\ University, Changchun 130033, People's \\ Republic of China; ${ }^{3}$ Department of \\ Cardiology, China-Japan Union Hospital, \\ Jilin University, Changchun 130033, \\ People's Republic of China
}

Backgrounds: microRNA-493-3p (miR-493) has been reported to be critically downregulated in multiple types of human cancer. However, the expression level, biological roles and underlying mechanism of miR-493 in tongue squamous cell carcinoma (TSCC) remain to be elucidated.

Methods: RT-qPCR was utilized for the determination of miR-493 expression in TSCC tissues and cell lines. The influence of miR-493 overexpression on TSCC cell proliferation, apoptosis, migration, invasion in vitro and tumor growth in vivo were explored via MTT assay, flow cytometry analysis, cell migration and invasion assays, and xenograft tumors in nude mice, respectively. Bioinformatics analysis, luciferase reporter assays, RT-qPCR and Western blotting were performed to clarify the potential mechanisms involved in the action of miR-493 in TSCC cells.

Results: miR-493 was significantly downregulated in TSCC tissues and cell lines. Decreased miR-493 expression was notably correlated with tumor differentiation, depth of invasion and TNM stage. Additionally, patients with TSCC having low miR-493 expression showed lower overall survival rate. Functionally, miR-493 upregulation inhibited TSCC cell proliferation, migration, invasion in vitro; induced cell apoptosis; and decreased the tumor growth in vivo. Bioinformatics analysis followed by luciferase reporter assays also demonstrated that miR-493 directly bound to the 3'-untranslated region of high-mobility group AT-hook 2 (HMGA2) in TSCC cells, and therefore reduced HMGA2 expression at the mRNA and protein level. Furthermore, HMGA2 was overexpressed in TSCC tissues and inversely correlated with miR-493. Moreover, silenced HMGA2 expression simulated the tumor-suppressing roles of miR-493 overexpression on TSCC cells. HMGA2 overexpression eliminated the inhibitory roles of miR-493 overexpression on TSCC cells.

Conclusion: These observations demonstrated that miR-493 is a tumor suppressor inhibited the oncogenicity of TSCC cells by directly targeting HMGA2. These results provide sufficient evidence for the miR-493/HMGA2 axis as a novel therapeutic target for the treatment of patients with TSCC in the future.

Keywords: tongue squamous cell carcinoma, microRNA-493, high-mobility group AT-hook 2 , gene therapy

\section{Introduction}

Oral cavity cancer is a devastating human malignancy with high morbidity and mortality. ${ }^{1}$ Approximately 300,000 novel cases and 130,000 oral cavity cancerassociated deaths are estimated to occur each year globally. ${ }^{2}$ Tongue squamous cell carcinoma (TSCC), the most commonly occurring type of oral cavity cancer, is characterized by its significantly aggressive biological nature with a high incidence of local or distant metastasis. ${ }^{3}$ Despite remarkable improvements in TSCC therapy, patient outcomes have not noticeably improved in the past few decades. ${ }^{4}$ To date,
Correspondence: Zhen Tian

Department of Cardiology, China-Japan

Union Hospital, Jilin University, No.126

Xiantai Road, Changchun, Jilin I30033,

People's Republic of China

Email Jilin_tianzhen@I63.com 
several risk factors, including human papillomavirus infection, excessive drinking and tobacco intake, have been identified to be involved in the oncogenesis and progression of TSCC. ${ }^{5,6}$ However, the detailed mechanisms underlying the pathogenesis of TSCC remain largely unknown. Therefore, the elucidation of relevant mechanisms underlying TSCC occurrence and development is necessary to identify novel therapeutic targets for the clinical management of patients with this disease.

microRNAs (miRNAs/miRs) are a cluster of short, endogenous, non-coding RNA molecules. ${ }^{7}$ They are approximately 18-24 nucleotides in length and negatively regulate genes expression through complete or incomplete base-pairing with the 3 '-untranslated regions (3'-UTRs) of their target genes to induce translational inhibition and/or mRNA degradation. ${ }^{8}$ Previous evidence has indicated that miRNAs account for only $1-3 \%$ of the human genome, but may modulate $>60 \%$ of all human protein-coding genes. ${ }^{9,10}$ With increasing research, a number of miRNAs have been found to be dysregulated in TSCC, such as miR-24, ${ }^{11}$ miR-183, ${ }^{12}$ miR-373 ${ }^{13}$ and miR-802. ${ }^{14}$ Furthermore, the aberrantly expressed miRNAs may function as tumor suppressor or oncogenes in TSCC and have significant regulatory roles in the disease. ${ }^{2,15}$ Therefore, it is important to detect miRNA expression and examine their roles in the development of TSCC in order to provide promising therapeutic targets for treating patients with TSCC.

miR-493-3p (miR-493) has been reported to be critically downregulated in multiple types of human cancer, including gastric cancer, ${ }^{16}$ melanoma, ${ }^{17}$ hepatocellular carcinoma ${ }^{18}$ and pancreatic cancer. ${ }^{19}$ However, the expression level, biological roles and underlying mechanism of miR-493 in TSCC remain to be elucidated.

In the present study, miR-493 expression was detected in TSCC tissues and cell lines. In addition, functional assays were performed to test the effects of miR-493 on TSCC cells. Furthermore, the potential mechanisms involved in the action of miR-493 in TSCC cells were clarified in detail.

\section{Materials and methods}

\section{Clinical specimens}

In total, 47 paired TSCC tissues and adjacent normal tissues (ANTs) were obtained from patients who received surgery at China-Japan Union Hospital of Jilin University. All patients enrolled in this research had not been treated with chemotherapy or radiotherapy prior to specimen collection. Tissues were snap-frozen and stored at $-80^{\circ} \mathrm{C}$ until further use. The present study was approved by the Ethics Committees of China-Japan Union Hospital of Jilin University and written informed consent was provided by all participants. All experimental procedures were carried out in accordance with the Declaration of Helsinki.

\section{Cell culture and transfection}

Normal gingival epithelial cells were obtained from the American Type Culture Collection [(ATCC) Manassas, VA, USA], and were cultured in minimum essential media supplemented with $10 \%$ fetal bovine serum (FBS), $100 \mathrm{U} / \mathrm{mL}$ penicillin and $100 \mathrm{mg} / \mathrm{mL}$ streptomycin (all from Gibco; Thermo Fisher Scientific, Inc., Waltham, MA, USA). In addition,two human TSCC cell lines (SCC-15, and CAL-27) were purchased from ATCC, while Tca8113 cell line was obtained from the Type Culture Collection of the Chinese Academy of Sciences (Shanghai, China). All aforementioned cell lines were maintained in RPMI-1640 medium containing 10\% FBS, $100 \mathrm{U} / \mathrm{mL}$ penicillin and $100 \mathrm{mg} / \mathrm{mL}$ streptomycin. All cell lines were grown at $37^{\circ} \mathrm{C}$ in a humidified $5 \%$ $\mathrm{CO}_{2} / 95 \%$ air atmosphere.

miR-493 mimics, negative control miRNA mimics (miRNC), small interfering RNA (siRNA) against the expression of high-mobility group AT-hook 2 (HMGA2; si-HMGA2) and negative control siRNA (si-NC) were obtained from Shanghai GenePharma Co., Ltd. (Shanghai, China). HMGA2 overexpression plasmid pcDNA3.1-HMGA2 and empty pcDNA3.1 plasmid were synthesized by Chinese Academy of Sciences (Changchun, China).

For transfection, cells were plated into 6-well plates with antibiotic free culture medium at a density of $6 \times 10^{5}$ cells per well. The next day, cells were transfected with the above miRNA mimics, siRNA or plasmid using Lipofectamine $^{\circledR} 2000$ reagent (Invitrogen; Thermo Fisher Scientific, Inc.), according to the manufacturer's guidelines. Cells were incubated at $37^{\circ} \mathrm{C}$ containing $5 \% \mathrm{CO}_{2} / 95 \%$ air. After $8 \mathrm{~h}$ of transfection, the culture medium was replaced with fresh RPMI-1640 medium containing 10\% FBS.

\section{RNA extraction and reverse transcription-quantitative polymerase chain reaction (Rt-qPCR)}

RT-qPCR was used to detect miR-493 and HMGA2 mRNA expression. Total RNA was extracted from tissue specimens or cells using TRIzol ${ }^{\circledR}$ reagent (Invitrogen; Thermo Fisher Scientific, Inc.). Total RNA concentration was determined 
using a Nanodrop 2000 (Thermo Fisher Scientific, Inc.). To measure miR-493 expression, total RNA was reverse-transcribed into cDNA using a TaqMan MicroRNA Reverse Transcription kit (Applied Biosystems; Thermo Fisher Scientific, Inc.). Next, qPCR was conducted using a TaqMan MicroRNA PCR kit (Applied Biosystems, Foster City, CA, USA). U6 was used as an internal reference for the quantification of miR-493 expression. For HMGA2 mRNA expression analysis, a PrimeScript RT Reagent kit (Takara Biotechnology Co., Ltd., Dalian, China) was used to synthesize cDNA, according to the manufacturer's protocol. Subsequently, HMGA2 mRNA expression was detected with a SYBR Premix Ex Taq ${ }^{\mathrm{TM}}$ Kit (Takara Biotechnology Co., Ltd.) on an Applied Biosystems 7500 Fast Real-Time PCR system (Applied Biosystems; Thermo Fisher Scientific, Inc.). GAPDH was used as an internal control for HMGA2 mRNA expression. Relative gene expression was calculated using the $2^{-\Delta \Delta \mathrm{Cq}}$ method. ${ }^{20}$

\section{MTT assay}

Cell proliferation was detected $24 \mathrm{~h}$ after transfection. Cells were harvested and inoculated in each well of a 96-well plate $\left(3 \times 10^{3}\right.$ cells/well). Cells were incubated at $37^{\circ} \mathrm{C}$ with $5 \% \mathrm{CO}_{2}$ for $0,24,48$ or $72 \mathrm{~h}$, and the MTT assay was performed at every time point. of MTT $(20 \mu \mathrm{l} ; 5 \mathrm{mg} / \mathrm{mL}$; Sigma-Aldrich; Merck KGaA, Darmstadt, Germany) was added into each well. Following incubation at $37^{\circ} \mathrm{C}$ for an additional $4 \mathrm{~h}$, culture medium was removed and replaced with $100 \mu \mathrm{l}$ dimethyl sulfoxide (Sigma-Aldrich; Merck KGaA, Darmstadt, Germany). Finally, the absorbance value of each well was determined by a microplate reader (BioTek Instruments, Inc., Winooski, VT, USA) at a wavelength of $490 \mathrm{~nm}$.

\section{Flow cytometry analysis of cell apoptosis}

The Annexin V-FITC apoptosis detection kit (BioLegend, San Diego, CA, USA) was utilized for the detection of cell apoptosis. In detail, cells transfected with the recombinant miRNAs, siRNA or plasmid were harvested after $48 \mathrm{~h}$ of incubation, washed thrice with ice-cold Phosphate Buffer solution (Gibco; Thermo Fisher Scientific), and then resuspended in $100 \mu \mathrm{L}$ of $1 \times$ binding buffer. The cell suspension was subjected to $5 \mu \mathrm{L}$ Annexin V-FITC and $5 \mu \mathrm{L}$ propidium iodide staining. The stained cells were subjected to a flow cytometer (FACScan, BD Biosciences, Heidelberg, Germany) for the detection of cell apoptosis rate.

\section{Cell migration and invasion assays}

Cells were harvested at $48 \mathrm{~h}$ post-transfection and suspended into FBS-free RPMI-1640 medium. Next, $5 \times 10^{4}$ transfected cells were placed in the upper chamber of Matrigel-coated Transwell inserts ( $8 \mu \mathrm{m}$ pore size; BD Biosciences, San Jose, CA, USA). The lower chambers were coated with $500 \mu \mathrm{L}$ RPMI-1640 medium containing 20\% FBS to serve as a chemo-attractant. After $24 \mathrm{~h}$ of incubation, non-invading cells were gently removed using a cotton swab, and invasive cells attached to the lower surface of the membrane were fixed with $4 \%$ paraformaldehyde and stained with $0.05 \%$ crystal violet. The invasive cells were photographed and counted in five randosy chosen visual fields under an inverted light microscope (IX83; Olympus Corporation, Tokyo, Japan). The experimental procedures of migration assay were similar with those of the invasion assay except that the Transwell inserts were non-coated with Matrigel.

\section{Xenograft tumors in nude mice}

All animal experiments were approved by the Animal Research committee of China-Japan Union Hospital, and carried out in accordance with the guidance of Animal Protection Law of the People's Republic of China-2009 for experimental animals. Four-week-old female nude mice were bought from the Model Animal Research Institute of Nanjing University, and were subcutaneously injected with miR-493 mimics or miR-NC-transfected Tca8113 cells. The width and length of tumor xenografts that formed in nude mice were detected every 2 days using Vernier calipers and tumor volumes were analyzed using the follows: tumor volume $(\mathrm{mm} 3)=$ width $\left(\mathrm{mm}^{2}\right) \times$ length $(\mathrm{mm}) / 2$. After 4 weeks, all nude mice were sacrificed and the tumor xenografts were excised, weighed and stored for further use.

\section{Identification of miR-493 targets}

TargetScan (www.targetscan.org) and miRanda (www. microrna.org) were utilized to predict the putative target genes of miR-493.

\section{Luciferase reporter assay}

The wild-type (WT) and mutant (MUT) 3'-UTR of HMGA2 containing the predicted binding site were produced by Shanghai GenePharma Co., Ltd., and inserted into the pmirGLO luciferase reporter vector (Promega Corporation, Madison, WI, USA). The constructed luciferase plasmids were defined as pmirGLO-HMGA2-3'-UTR WT and pmirGLO-HMGA2-3'-UTR MUT, respectively. Luciferase 
reporter plasmids along with miR-493 mimics or miR-NC were transfected into cells using Lipofectamine ${ }^{\circledR} 2000$ reagent, in accordance with the manufacturer's instructions. At $48 \mathrm{~h}$ post-transfection, luciferase activity was detected using the Dual-Luciferase ${ }^{\circledR}$ Reporter Assay system (Promega Corporation, Madison, WI, USA), following the manufacturer's instructions. Firefly luciferase activity was normalized to Renilla luciferase activity.

\section{Western blot analysis}

Total protein was extracted from tissues or cells using cold radioimmunoprecipitation assay buffer (Nanjing KeyGen Biotech Co., Ltd, Nanjing, China), and the concentration of total protein was measured using a bicinchoninic acid assay kit (Nanjing KeyGen Biotech Co., Ltd). Equal amounts of protein were separated on $10 \%$ sodium dodecyl sulfate polyacrylamide gel, transferred onto polyvinylidene fluoride membranes and blocked at room temperature for $2 \mathrm{~h}$ with Tris-buffered saline containing $0.1 \%$ Tween-20 (TBST) containing 5\% fat-free milk. Next, the membranes were incubated overnight at $4{ }^{\circ} \mathrm{C}$ with primary antibodies against HMGA2 (1:1,000 dilution; cat. no. ab97276; Abcam, Cambridge, UK) or GAPDH (1:1,000 dilution; cat. no. ab128915; Abcam). Following a wash with TBST, membranes were incubated with goat anti-rabbit horseradish peroxidase-conjugated second antibody (1:5,000 dilution; cat. no. ab6721; Abcam) at room temperature for $2 \mathrm{~h}$. The membranes were then washed again with TBST. Protein bands were visualized using enhanced chemiluminescence reagent (Pierce; Thermo Fisher Scientific, Inc.). GAPDH was used as an internal control for HMGA2 protein expression.

\section{Statistical analysis}

All data were expressed as the mean \pm standard deviation. SPPS 17.0 software (SPSS, Inc., Chicago, IL, USA) was used for statistical analysis. Differences between groups were examined using Student's t-tests or one-way analysis of variance followed by the Student-Newman-Keuls post-hoc test. The chi-square test was used to evaluate the association between miR-493 expression and clinicopathological characteristics in patients with TSCC. The Kaplan-Meier method was used to calculate the survival curve, and log-rank test to determine statistical significance. Spearman's correlation analysis was performed to test the correlation between miR493 and HMGA2 mRNA expression in TSCC tissues. $P<0.05$ was considered to indicate a statistically significant difference.

\section{Results}

\section{miR-493 expression is reduced in TSCC and indicates poor prognosis}

miR-493 has been reported to be dysregulated in several human malignancies (16-19). However, its expression pattern in TSCC remains unknown. In the present study, the expression of miR-493 was measured in 47 pairs of TSCC tissues and adjacent normal tissues (ANTs) by RT-qPCR. The results revealed that miR-493 expression was significantly downregulated in TSCC tissues compared with that in ANTs (Figure 1A; $P<0.05$ ). Subsequently, miR-493 expression was detected in three human TSCC cell lines (SCC-15, Tca8113 and CAL-27) and normal gingival epithelial cells. RT-qPCR showed that miR-493 expression in TSCC cell lines was significantly reduced, compared with that in normal gingival epithelial cells (Figure 1B; $P<0.05$ ).
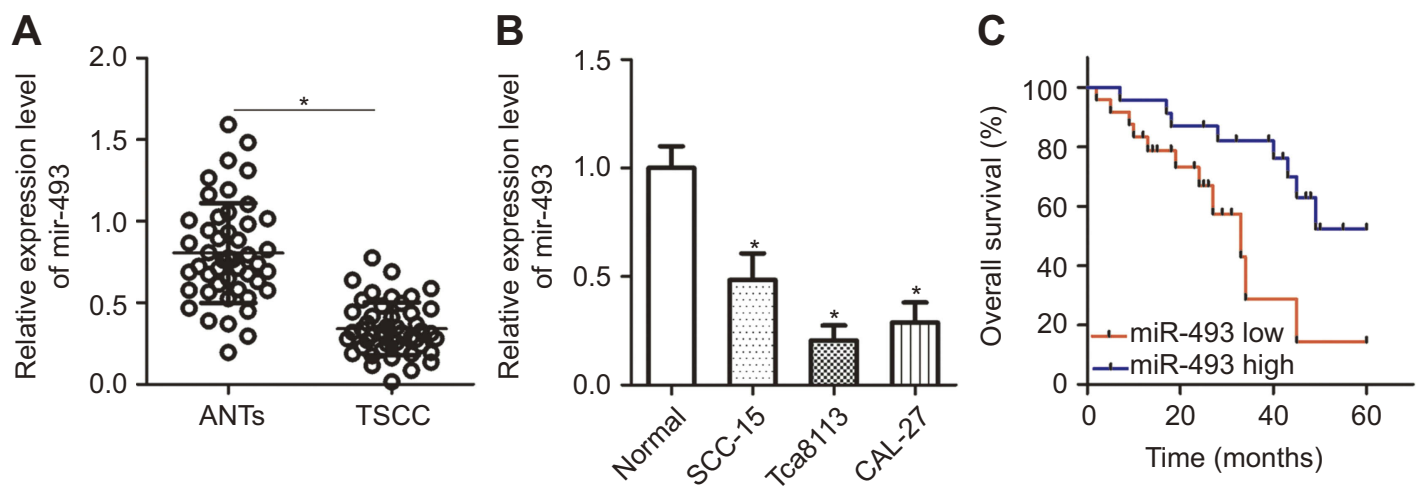

Figure I miR-493 expression is significantly downregulated in TSCC tissues and cell lines. (A) RT-qPCR was used to determine miR-493 expression in 47 pairs of TSCC tissues and ANTs. $* P<0.05$ vs ANTs. (B) RT-qPCR was used to measure the expression of miR-493 in three human TSCC cell lines (SCC-I5, Tca8II3, and CAL-27) and normal gingival epithelial cells. $* P<0.05$ vs normal gingival epithelial cells. (C) Kaplan-Meier curves for overall survival in patients with TSCC according to miR-493 expression. 
To evaluate the clinical value of miR-493 in patients with TSCC, all enrolled patients were classified into two groups according to the median value of miR-493 in TSCC tissues: the low and high miR-493 expression groups. As shown in Table 1, decreased miR-493 expression was obviously correlated with tumor differentiation $(P=0.039)$, depth of invasion $(P=0.020)$ and TNM stage $(P=0.042)$. In addition, patients with TSCC having low miR-493 expression showed lower overall survival rate compared with patients having high miR-493 expression (Figure $1 \mathrm{C} ; P=0.0138$ ). The results suggested that miR493 was downregulated in TSCC, and miR-493 downregulation may have served an important role in TSCC tumorigenesis and development.

\section{miR-493 overexpression inhibits the proliferation, migration, invasion and induces the apoptosis of TSCC cells}

To clarify the biological impact of miR-493 in TSCC, Tca8113 and CAL-27 cells were transfected with miR-493 mimics or miR-NC. Cells were collected and subjected to

Table I The association of miR-493 expression with clinicopathologic features in patients with TSCC

\begin{tabular}{|c|c|c|c|}
\hline Features & $\begin{array}{l}\text { Low miR-493 } \\
\text { group }(n=24)\end{array}$ & $\begin{array}{l}\text { High } \\
\text { miR-493 } \\
\text { group }(n=23)\end{array}$ & $P$ \\
\hline $\begin{array}{l}\text { Gender } \\
\text { Male } \\
\text { Female }\end{array}$ & $\begin{array}{l}17 \\
7\end{array}$ & $\begin{array}{l}12 \\
11\end{array}$ & 0.238 \\
\hline $\begin{array}{l}\text { Age (years) } \\
\quad<50 \\
\geq 50\end{array}$ & $\begin{array}{l}5 \\
19\end{array}$ & $\begin{array}{l}10 \\
13\end{array}$ & 0.125 \\
\hline $\begin{array}{l}\text { Tumor } \\
\text { differentiation } \\
\text { Well and moderate } \\
\text { Poor }\end{array}$ & $\begin{array}{l}10 \\
14\end{array}$ & $\begin{array}{l}17 \\
6\end{array}$ & $0.039^{\circ}$ \\
\hline $\begin{array}{l}\text { Depth of invasion } \\
\quad<1 \mathrm{~cm} \\
\geq 1 \mathrm{~cm}\end{array}$ & $\begin{array}{l}7 \\
17\end{array}$ & $\begin{array}{l}15 \\
8\end{array}$ & $0.020^{\mathrm{a}}$ \\
\hline $\begin{array}{l}\text { TNM stage } \\
\text { I-II } \\
\text { III-IV }\end{array}$ & $\begin{array}{l}8 \\
16\end{array}$ & $\begin{array}{l}15 \\
8\end{array}$ & $0.042^{\mathrm{a}}$ \\
\hline $\begin{array}{c}\text { Relapse } \\
\text { No } \\
\text { Yes }\end{array}$ & $\begin{array}{l}11 \\
13\end{array}$ & $\begin{array}{l}14 \\
9\end{array}$ & 0.385 \\
\hline
\end{tabular}

Note: ${ }^{a} p<0.05$.
RT-qPCR to evaluate transfection efficiency $48 \mathrm{~h}$ post-transfection. miR-493 was markedly overexpressed by miR-493 mimics in Tca8113 and CAL-27 cells (Figure 2A; $P<0.05$ ). MTT assay and flow cytometry analysis were performed to investigate the impact of miR-493 overexpression on TSCC cell proliferation and apoptosis. The results demonstrated that miR-493 upregulation in Tca8113 and CAL-27 cells significantly decreased the cell proliferation (Figure 2B; $P<0.05$ ) and promoted the cell apoptosis (Figure 2C; $P<0.05$ ), compared with the miR-NC group. Furthermore, cell migration and invasion assays demonstrated that miR493 mimics transfection significantly reduced Tca8113 and CAL-27 cell migration (Figure 2D; $P<0.05$ ) and invasion (Figure 2E; $P<0.05$ ), compared with cells transfected with miR-NC. Thus, these data suggested that miR-493 may have served tumor suppressive roles in the progression of TSCC.

\section{HMGA2 is a direct target of miR-493 in TSCC cells}

To further identify the molecular mechanism by which miR493 restrained TSCC progression, bioinformatics analysis was applied to predict the putative target genes of miR-493. HMGA2, frequently reported to be associated with the occurrence and development of TSCC, ${ }^{21,22}$ was predicted as a candidate of miR-493 and was selected for further identification (Figure 3A). To confirm this prediction, luciferase reporter plasmids were constructed and transfected into Tca8113 and CAL-27 cells with miR-493 mimics or miR-NC. Luciferase reporter assays indicated that luciferase activity was significantly reduced in Tca 8113 and CAL-27 cells co-transfected with miR-493 mimics and luciferase reporter plasmid carrying the wild-type binding site $(P<0.05)$. Whereas co-transfection of miR-493 mimics and mutant 3'-UTR of HMGA2 failed to affect luciferase activity (Figure 3B). Subsequent RT-qPCR and Western blot analysis demonstrated that enforced miR-493 expression markedly reduced HMGA2 mRNA (Figure 3C; $P<0.05$ ) and protein (Figure 3D; $P<0.05$ ) expression levels in Tca8113 and CAL-27 cells, compared with the control. These results demonstrated that HMGA2 was a direct target gene of miR-493 in TSCC cells.

\section{miR-493 expression is inversely correlated with HMGA2 expression in TSCC tissues}

To further determine the relationship between miR-493 and HMGA2 in TSCC, HMGA2 expression in TSCC 
A

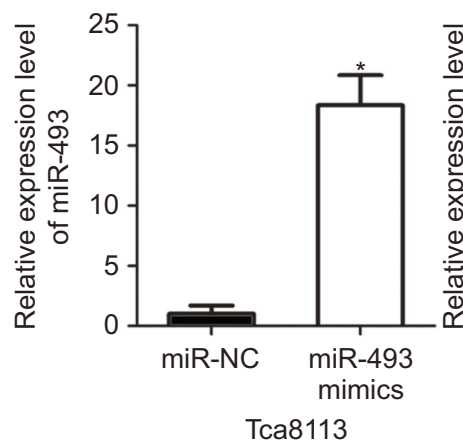

C

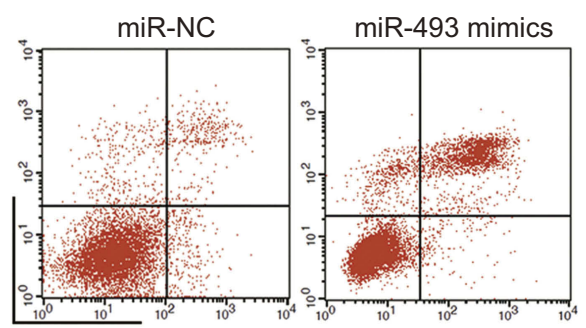

Annexin V

Tca8113

D

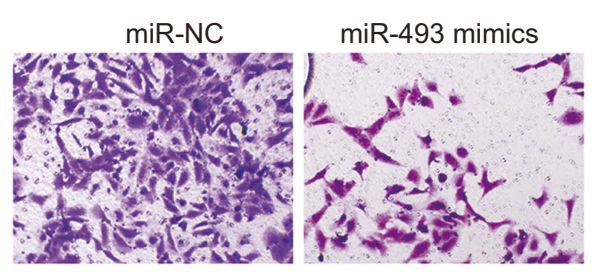

Tca8113

E

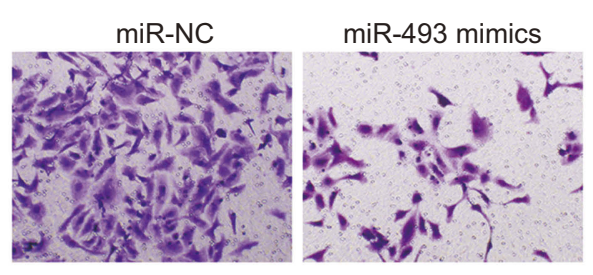

Tca8113
B
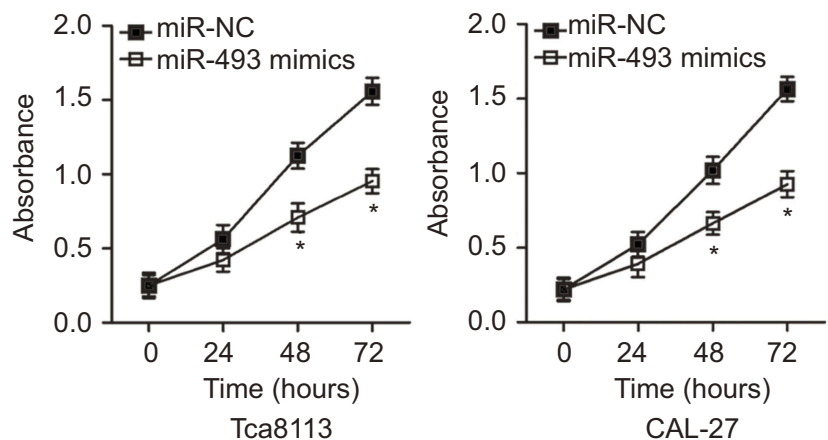

CAL-27

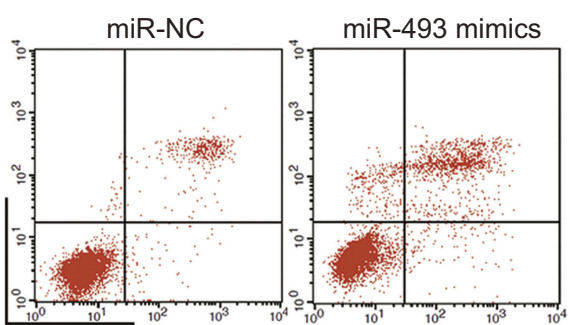

Annexin V

CAL-27
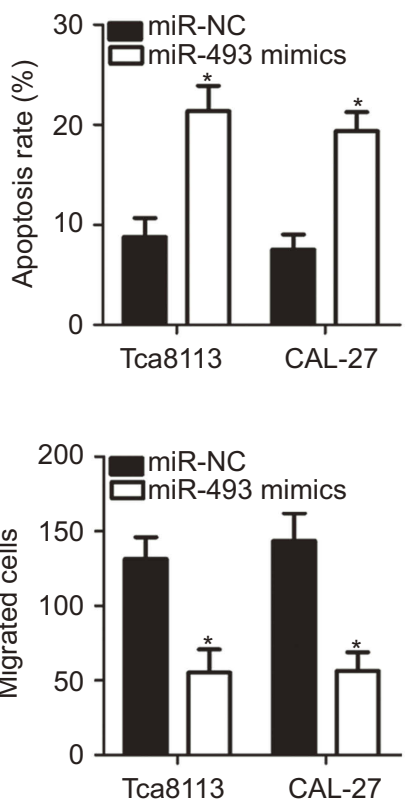

CAL-27
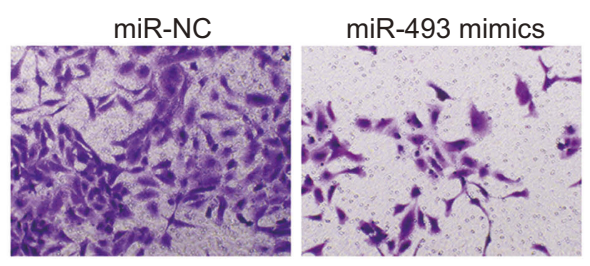

CAL-27

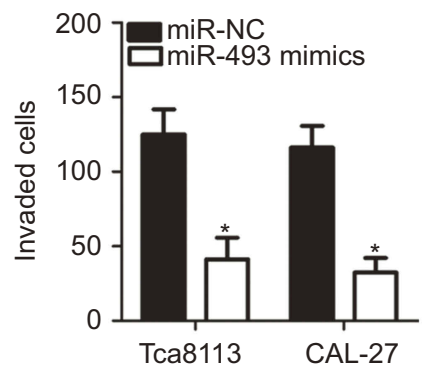

Figure 2 Exogenous miR-493 expression inhibits Tca8II 3 and CAL-27 cell proliferation, migration and invasion as well as induces cell apoptosis. (A) Tca8I I 3 and CAL-27 cells were treated with miR-493 mimics or miR-NC. The transfected cells were collected at $48 \mathrm{~h}$ post-transfection and subjected to reverse transcription-quantitative polymerase chain reaction analysis for miR-493 expression. (B, C) MTT assay and flow cytometry analysis were used to detect the proliferation and apoptosis of Tca8I I 3 and CAL-27 cells transfected with miR-493 mimics or miR-NC. (D, E) The migratory and invasive capacity of Tca8II 3 and CAL-27 cells following transfection with miR-493 mimics or miR-NC was assessed by cell migration and invasion assays. $* P<0.05$ vs miR-NC.

tissues and ANTs was detected. RT-qPCR analysis showed that TSCC tissues had high HMGA2 mRNA expression, compared with the ANTs (Figure $4 \mathrm{~A} ; P<0.05$ ). In addition, HMGA2 mRNA expression in TSCC tissues was negatively correlated with miR-493 expression (Figure 4B;
$\left.\mathrm{R}^{2}=0.3987, P<0.0001\right)$. Moreover, patients with TSCC harboring high miR-493 expression exhibited lower HMGA2 mRNA (Figure 4C; $P<0.05$ ) and protein (Figure 4D; $P<0.05$ ) levels than those patients having low miR-493 expression. These results suggested that 


\section{A}
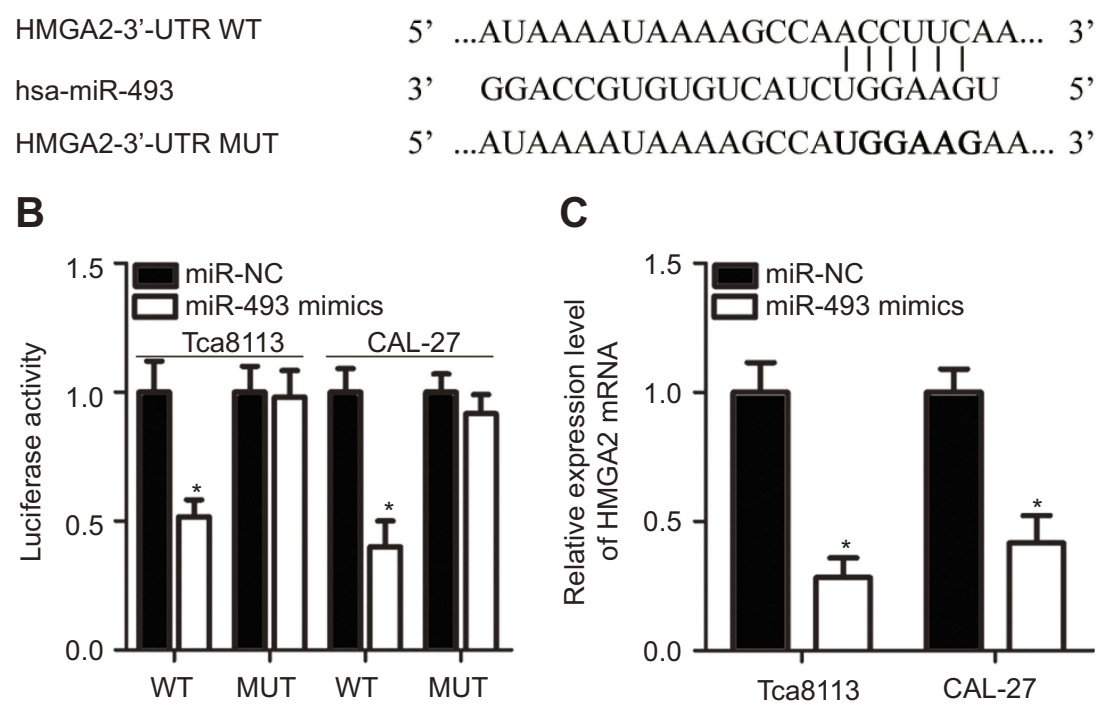

D
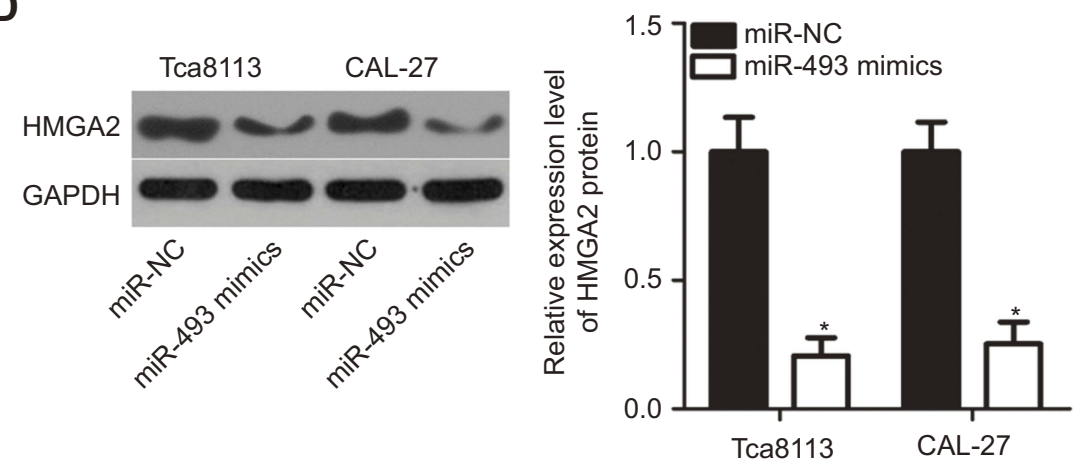

Figure 3 HMGA2 is a direct target of miR-493 in TSCC. (A) The putative WT binding site of miR-493 in the 3'-UTR of HMGA2 was predicted by bioinformatics analysis. The MUT binding sequences in the 3'-UTR of HMGA2 are also presented. (B) miR-493 mimics or miR-NC were co-transfected with luciferase reporter vectors carrying the wild-type or mutant 3'-UTR of HMGA2 into Tca8II3 and CAL-27 cells. Luciferase activity was detected 48 h post-transfection. (C, D) Expression of HMGA2 mRNA and protein in transfected Tca8II3 and CAL-27 cells was assessed by reverse transcription-quantitative polymerase chain reaction analysis and Western blot analysis, respectively. ${ }^{*} P<0.05$ vs miR-NC.

HMGA2 upregulation in TSCC tissues may be, at least partially, caused by miR-493 downregulation.

\section{Inhibition of HMGA2 performs an inhibitory effect on the malignant phenotype of TSCC cells}

To further evaluate the biological roles of HMGA2 on TSCC cells, siRNA against the expression of HMGA2 (si-HMGA2) was used to silence HMGA2 expression in Tca8113 and CAL-27 cells. The efficiency of silencing HMGA2 expression was confirmed via Western blotting (Figure 5A; $P<0.05$ ). It was observed that downregulation of HMGA2 suppressed the proliferation (Figure 5B; $P<0.05$ ) and induced the apoptosis (Figure 5C; $P<0.05$ ) of Tca8113 and CAL-27 cells. Furthermore, cell migration and invasion assays were carried out to assess the impact of HMGA2 silencing on TSCC cell migration and invasion. HMGA2 knockdown remarkably abated both migration (Figure 5D; $P<0.05$ ) and invasion (Figure 5E; $P<0.05)$ of Tca8113 and CAL-27 cells compared with that in si-NC-transfected cells. These results demonstrated that the effects of HMGA2 silencing were consistent with those induced by miR-493 overexpression, suggesting HMGA2 as a downstream effector of miR-493 in TSCC cells.

\section{HMGA2 restoration prevents the inhibitory effects of miR-493 in TSCC cells}

To evaluate whether the suppressive roles of miR-493 in TSCC cells were mediated by HMGA2, rescue experiments were performed by overexpressing HMGA2 with 

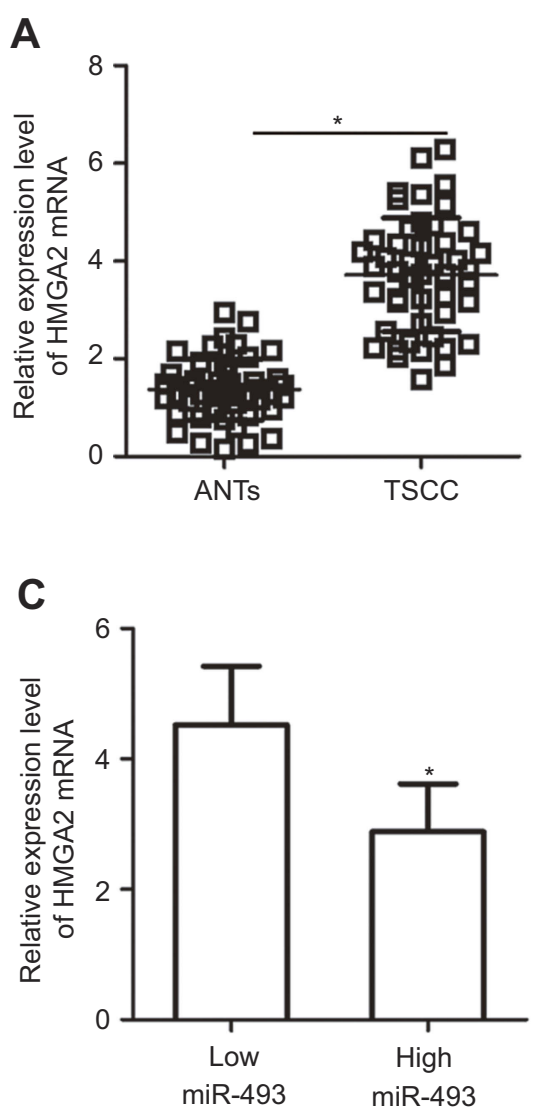

B

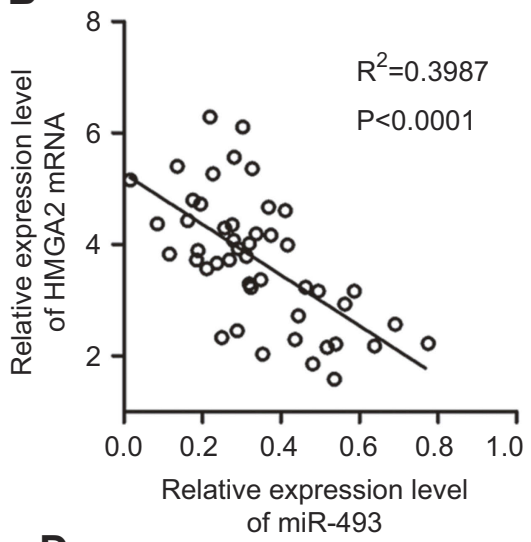

D
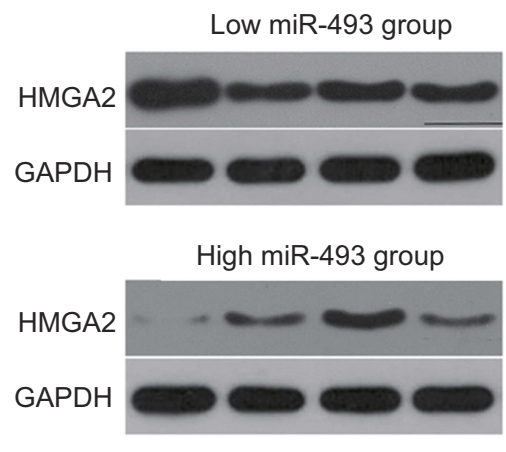

Figure 4 Expression of miR-493 is inversely correlated with HMGA2 expression in TSCC tissues. (A) HMGA2 mRNA expression in 47 pairs of TSCC tissues and ANTs was examined by reverse transcription-quantitative polymerase chain reaction analysis. ${ }^{*} P<0.05$ vs ANTs. (B) A statistically significant inverse correlation between miR-493 and HMGA2 mRNA levels in TSCC tissues was identified using Spearman's correlation analysis. $R^{2}=0.3987, P<0.0001$. (C, D) The expression of HMGA2 mRNA and protein in TSCC patients with high miR-493 expression was lower than that in patients with low miR-493 expression. $* P<0.05$ vs low miR-493 expression.

pcDNA3.1-HMGA2 plasmid transfection. Western blot analysis confirmed that the decreased HMGA2 protein expression in miR-493 overexpressing-Tca8113 and CAL-27 cells was restored after cotransfection with pcDNA3.1-HMGA2 (Figure 6A; $P<0.05$ ). Furthermore, HMGA2 overexpression abolished the tumor-suppressing effects of miR-493 overexpression on Tca8113 and CAL-27 cell proliferation (Figure 6B; $P<0.05$ ), apoptosis (Figure 6C; $P<0.05$ ), migration (Figure 6D; $P<0.05$ ) and invasion (Figure $6 \mathrm{E} ; P<0.05$ ). These results indicated that miR-493 inhibited TSCC cells, partly by decreasing HMGA2 expression.

\section{miR-493 functionally decreases tumor growth of TSCC in vivo}

Xenograft tumors in nude mice were finally employed to determine the impact of miR-493 on tumor growth in vivo. The tumor growth was notably impaired in the miR-493 mimics group compared with in miR-NC group (Figure 7A and $\mathrm{B} ; P<0.05$ ). Further analysis indicated that the tumor weight was suppressed in the miR-493 mimics group (Figure $7 \mathrm{C} ; P<0.05$ ). RT-qPCR analysis revealed that miR-493 was still overexpressed in the tumor xenografts obtained from miR-493 mimics group (Figure 7D; $P<0.05$ ). Finally, the expression of HMGA2 protein was decreased in the miR-493 mimics group compared with that in the miR-NC group (Figure 7E; $P<0.05$ ). Our results suggested that miR-493 overexpression impaired the tumor growth of TSCC in vivo.

\section{Discussion}

Emerging evidence has revealed that aberrantly expressed miRNAs have strong associations with TSCC formation and progression by acting as tumor suppressors or oncogenes. $^{23-25}$ Therefore, further investigation on the roles of miRNAs in TSCC may contribute towards finding effective therapeutic targets for patients with TSCC. In the present study, it was found that miR-493 expression was obviously downregulated in TSCC, and its downregulation was significantly correlated with tumor differentiation, 


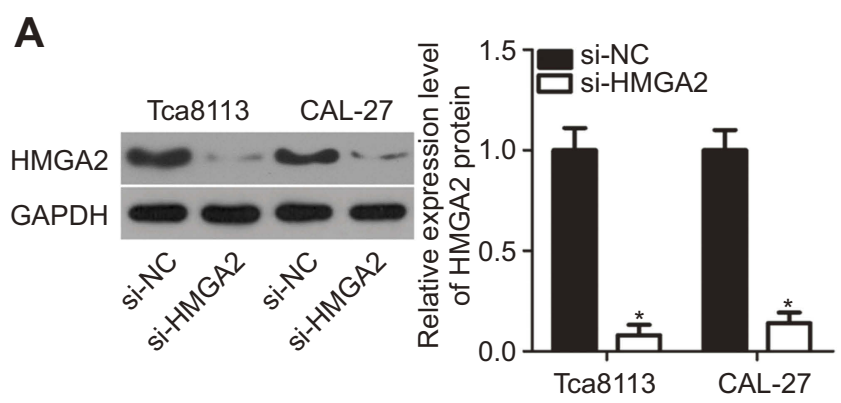

C

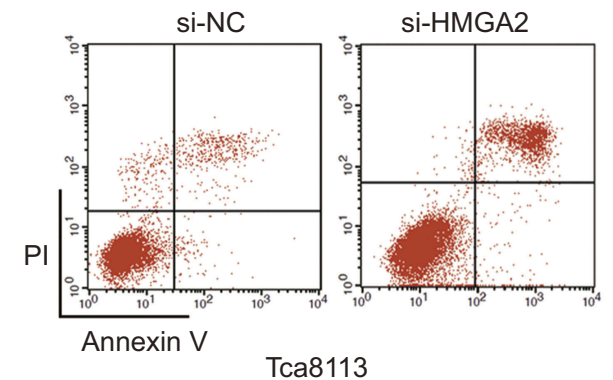

D

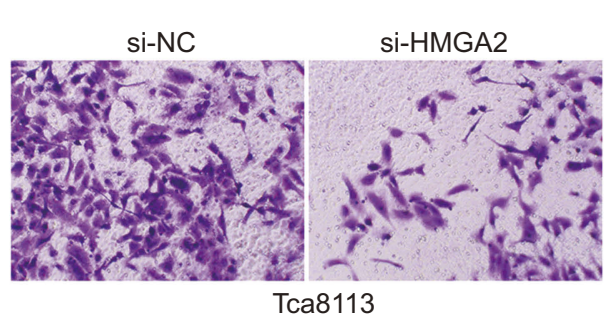

E

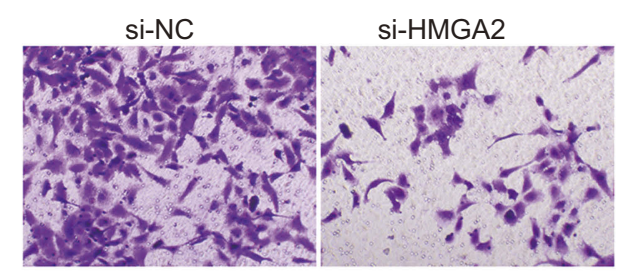

Tca8113
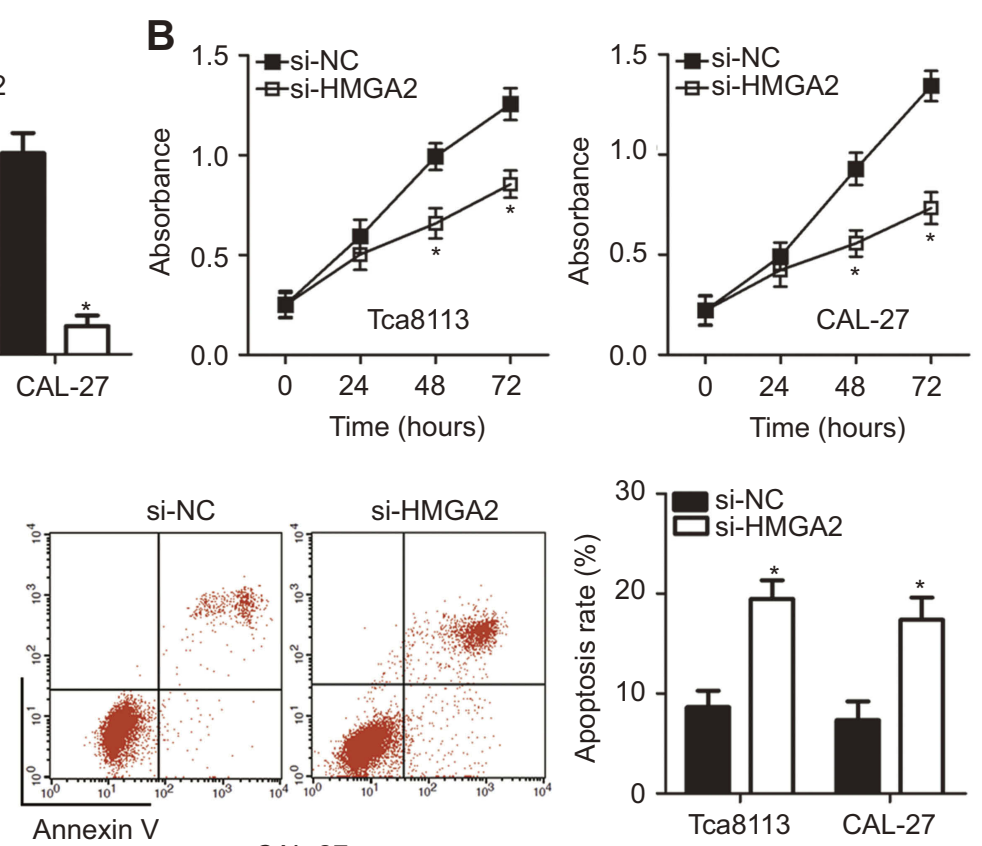

CAL-27
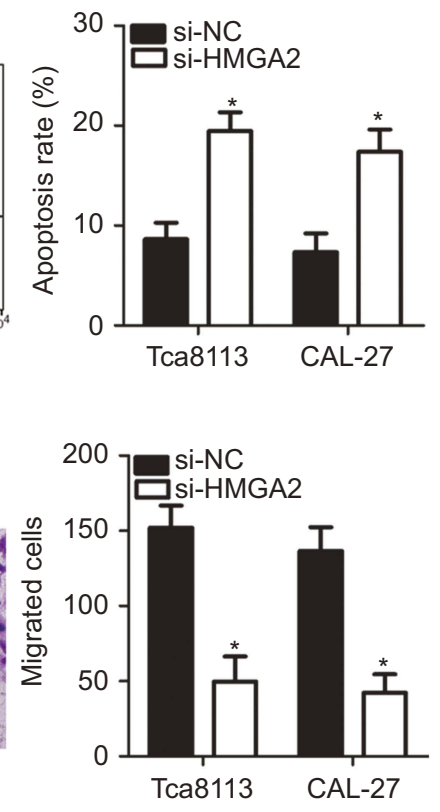

CAL-27

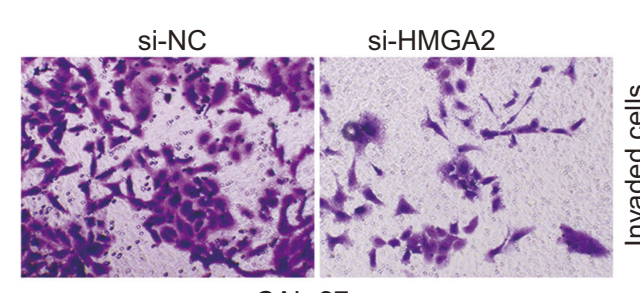

CAL-27

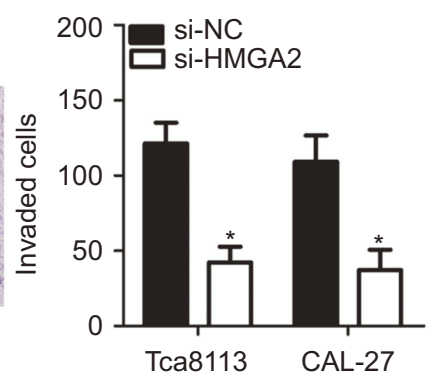

Figure 5 HMGA2 knockdown simulates the action of miR-493 overexpression in TSCC cells. (A) Si-HMGA2 or si-NC was introduced into Tca8II3 and CAL-27 cells. After transfection, HMGA2 protein expression was determined via Western blot analysis. ${ }^{*} P<0.05$ vs si-NC. (B-E) The proliferation, apoptosis, migration and invasion of HMGA2 decreasing-Tca8II 3 and CAL-27 cells was explored using MTT assay, flow cytometry analysis and cell migration and invasion assays, respectively. $* P<0.05$ vs si-NC.

depth of invasion, TNM stage and worse overall survival. Functional experiments revealed that miR-493 upregulation suppressed the proliferation, migration, invasion, promoted the apoptosis and hindered the tumor growth of TSCC cells. Furthermore, HMGA2 was identified as a direct target gene of miR-493. In addition, HMGA2 expression was upregulated in TSCC tissues, and the upregulation of HMGA2 was inversely correlated with miR-493. Furthermore, silenced HMGA2 expression imitated the tumor-suppressing roles of miR-493 upregulation in TSCC cells. HMGA2 restoration partially prevented the miR-493-mediated suppression of TSCC cell growth and metastasis in vitro. These results suggested that miR-493 may play tumor suppressive roles in the development of TSCC by directly targeting HMGA2. This finding further indicated that miR-493 may have potential as a therapeutic target for patients with this disease. 
A
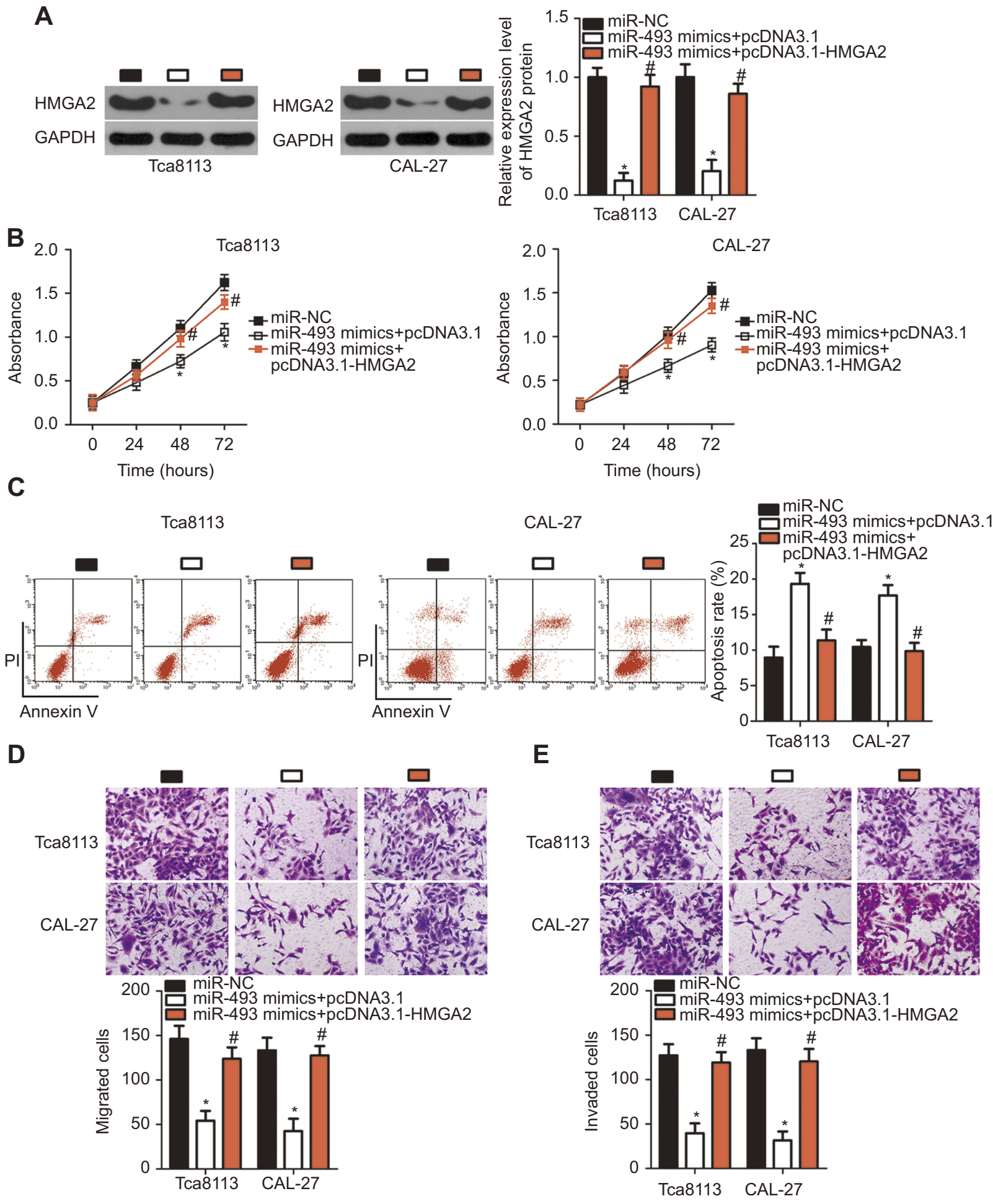

Figure 6 Overexpression of HMGA2 inhibits the tumor-suppressive effects of miR-493 in Tca8II3 and CAL-27 cells. (A) HMGA2 protein expression was detected by Western blot analysis after miR-493 overexpressing-Tca8II 3 and CAL-27 cells were cotransfected with pcDNA3.I-HMGA2 or pcDNA3.I. *P<0.05 vs miR-NC; ${ }^{*} P<0.05$ vs miR-493 mimics+pcDNA3.I-HMGA2. (B-E) Cell proliferation, apoptosis, migration and invasion was determined in Tca8II3 and CAL-27 cells transfected with miR-493 mimics in combination with either pcDNA3.I-HMGA2 or $p c D N A 3.1$. ${ }^{*} P<0.05$ vs miR-NC; ${ }^{\#} P<0.05$ vs miR-493 mimics + pcDNA3.I-HMGA2.

miR-493 has been reported to be abnormally expressed in several types of human cancer. For example, miR-493 expression was downregulated in gastric cancer tissues and cell lines. Low miR-493 expression was correlated with the clinical stage and lymph node metastases of gastric cancer patients. ${ }^{16}$ In addition, patients with 


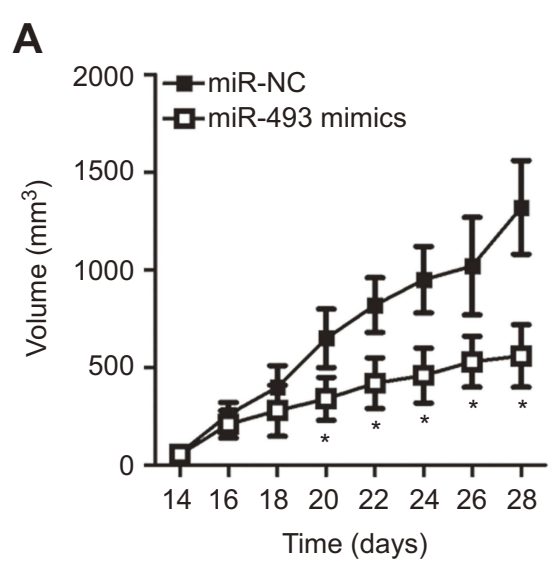

C

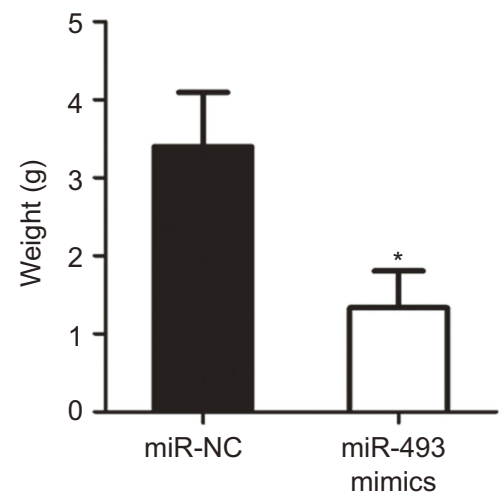

$\mathbf{E}$

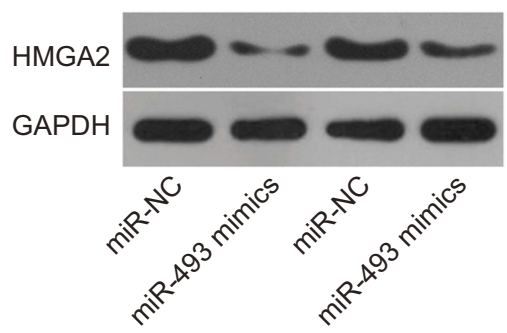

B

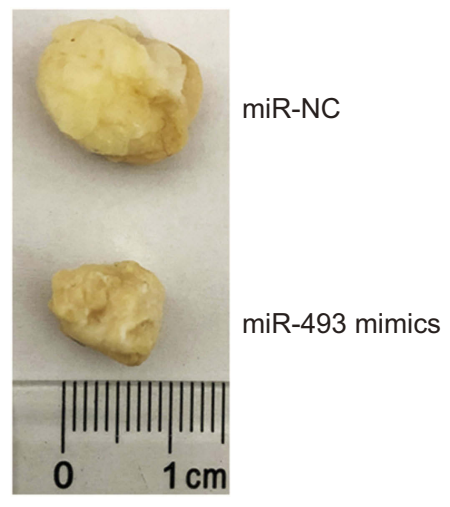

D
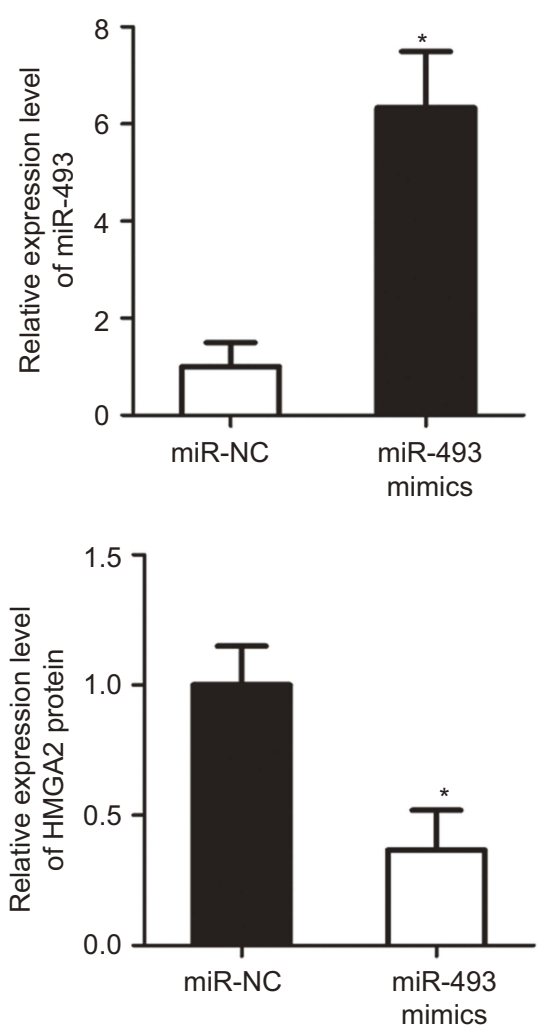

Figure 7 miR-493 upregulation decreases tumor growth in vivo. (A) The growth curves of tumor xenograft formed in the nude mice were analyzed. $* P<0.05$ vs miR-NC. (B) Photograph of tumor xenograft derived from the nude mice injected with miR-493 mimics or miR-NC-transfected Tca8II 3 cells. (C) Tumor weigh excised from nude mice in miR-493 mimics and miR-NC groups. $* P<0.05$ vs miR-NC. (D) The expression of miR-493 in tumor xenograft was examined through RT- $q P C R$ analysis. $* P<0.05$ vs miR-NC. (E) The protein expression of HMGA2 in the tumor xenograft that were transfected with miR-493 mimics or miR-NC was detected by Western blotting. $* P<0.05$ vs miR-NC.

decreased miR-493 expression had a shorter overall survival and relapse free survival, compared with patients with high miR-493 expression. ${ }^{16}$ Downregulation of miR-493 was also observed in melanoma, ${ }^{17}$ hepatocellular carcinoma, ${ }^{18}$ pancreatic cancer, ${ }^{19}$ prostate cancer, ${ }^{26}$ bladder cancer $^{27}$ and nonsmall-cell lung cancer. ${ }^{28}$ These findings suggested that miR-493 may be a potential diagnostic biomarker for these types of human cancer.
miR-493 dysregulation is closely implicated in the progression and development of several human cancer types. For instance, miR-493 expression restoration markedly inhibits the proliferation and metastasis of gastric cancer cells in vitro and in vivo. ${ }^{16}$ In melanoma, miR-493 upregulation inhibits cell proliferation and induces cell cycle arrest. ${ }^{17}$ In hepatocellular carcinoma, enforced miR-493 expression significantly restricts cell growth in vitro and in vivo, and 
decreases cell metastasis in vitro. ${ }^{18}$ In pancreatic cancer, ectopic expression of miR-493 suppresses cell proliferation and invasion. ${ }^{19}$ In bladder cancer, miR-493 overexpression attenuated cell growth and motility in vitro. ${ }^{27}$ In non-small cell lung cancer, miR-493 expression represses cell growth, invasion and metastasis. ${ }^{28}$ In ovarian cancer, exogenous of miR-493 expression promotes cellular apoptosis, resulting in breakdown of mitochondrial membrane potential and the activation of Caspases resulting in the fragmentation of DNA. $^{29}$ All these findings indicate the roles of miR-493 in carcinogenesis and cancer progression and suggest that miR-493 may present a path to novel therapeutic strategies for managing patients with these specific cancer types.

Several genes, including RhoC, ${ }^{16}$ IRS4, ${ }^{17}$ ANTXR1, ${ }^{18}$ RSPO $2,{ }^{18} \mathrm{hERG}^{1,}{ }^{19} \mathrm{FZD}^{27}$ and E2F1, ${ }^{28}$ have been previously identified as direct targets of miR-493. In a recently published paper, AKT2, STK38L, HMGA2, ETS1 and E2F5 were revealed as direct target genes of miR-493 in ovarian cancer. ${ }^{29}$ HMGA2, a member of the high mobility group A protein family, was confirmed as a direct target of miR-493 in TSCC. HMGA2 is a non-histone chromatinbinding protein and is overexpressed in multiple types of human malignancy, such as colorectal, ${ }^{30}$ bladder, $^{31}$ gastric $^{32}$ and lung ${ }^{33}$ cancers. HMGA2 expression is also highly expressed in TSCC, and HMGA2 overexpression is strongly associated with recurrence, clinical stage, lymph node metastasis and histological differentiation of patients with TSCC. ${ }^{21,22}$ TSCC patients with high HMGA2 expression have shorter overall survival time, compared with patients with low HMGA2 expression. ${ }^{21}$ In addition, multivariate survival analysis identified HMGA2 as an independent biomarker for predicting the prognosis of patients with TSCC. ${ }^{21}$ Furthermore, HMGA2 may promote TSCC tumor aggression by affecting cell proliferation, cell cycle, migration, invasion, metastasis and epithelial-mesenchymal transition. $^{21,22}$ Therefore, miR-493-mediated targeted therapy against HMGA2 expression may be a novel potential therapeutic technique for monitoring and treating patients with TSCC.

In this study, we did not perform rescue experiment in vivo to verify the regulatory relationship between miR-493 and HAMG2 in vivo. It was a limitation of our study, and we will resolve it in our following experiments

\section{Conclusion}

The present study demonstrated the evident downregulation of miR-493 expression in TSCC tissues and cell lines. In addition, the restoration of miR-493 expression inhibited the malignancy of TSCC cells by directly targeting HMGA2. These findings suggested that miR-493 and its target HMGA2 may be developed as therapeutic targets for patients with TSCC.

\section{Disclosure}

The authors declare that they have no competing interests in this work.

\section{References}

1. Torre LA, Bray F, Siegel RL, Ferlay J, Lortet-Tieulent J, Jemal A. Global cancer statistics, 2012. CA Cancer J Clin. 2015;65(2):87-108. doi: $10.3322 /$ caac. 21262

2. Yu X, Li Z. MicroRNA expression and its implications for diagnosis and therapy of tongue squamous cell carcinoma. J Cell Mol Med. 2016;20(1):10-16. doi:10.1111/jcmm. 12650

3. Xie N, Wang C, Liu X, et al. Tumor budding correlates with occult cervical lymph node metastasis and poor prognosis in clinical earlystage tongue squamous cell carcinoma. J Oral Pathol Med. 2015;44 (4):266-272. doi:10.1111/jop.12242

4. Warnakulasuriya S. Global epidemiology of oral and oropharyngeal cancer. Oral Oncol. 2009;45(4-5):309-316. doi:10.1016/j.oraloncology. 2008.06.002

5. El-Husseiny G, Kandil A, Jamshed A, et al. Squamous cell carcinoma of the oral tongue: an analysis of prognostic factors. $\mathrm{Br} \mathrm{J} \mathrm{Oral}$ Maxillofac Surg. 2000;38(3):193-199. doi:10.1054/bjom.1999.0235

6. Rodrigues PC, Miguel MC, Bagordakis E, et al. Clinicopathological prognostic factors of oral tongue squamous cell carcinoma: a retrospective study of 202 cases. Int J Oral Maxillofac Surg. 2014;43 (7):795-801. doi:10.1016/j.ijom.2014.01.014

7. Bartel DP. MicroRNAs: genomics, biogenesis, mechanism, and function. Cell. 2004;116(2):281-297. doi:10.1016/s0092-8674(04) 00045-5

8. Hammond SM. An overview of microRNAs. Adv Drug Deliv Rev. 2015;87:3-14. doi:10.1016/j.addr.2015.05.001

9. Manikandan J, Aarthi JJ, Kumar SD, Pushparaj PN. Oncomirs: the potential role of non-coding microRNAs in understanding cancer. Bioinformation. 2008;2(8):330-334. doi:10.6026/97320630002330

10. Economou EK, Oikonomou E, Siasos G, et al. The role of microRNAs in coronary artery disease: from pathophysiology to diagnosis and treatment. Atherosclerosis. 2015;241(2):624-633. doi:10.1016/j.atherosclerosis.2015.06.037

11. Zhao J, Chi J, Gao M, Zhi J, Li Y, Zheng X. Loss of PTEN expression is associated with high microRNA 24 level and poor prognosis in patients with tongue squamous cell carcinoma. $J$ Oral Maxillofac Surg. 2017;75(7):1449e1441-1449 e1448. doi:10.1016/j.joms.2017. 03.025

12. Yan D, Cai X, Feng Y. miR-183 modulates cell apoptosis and proliferation in tongue squamous cell carcinoma SCC25 cell line. Oncol Res. 2016;24(6):399-404. doi:10.3727/096504016X14685034103239

13. Weng J, Zhang H, Wang C, et al. miR-373-3p targets DKK1 to promote EMT-induced metastasis via the Wnt/beta-catenin pathway in tongue squamous cell carcinoma. Biomed Res Int. 2017;2017: 6010926. doi:10.1155/2017/6010926

14. Wu X, Gong Z, Sun L, Ma L, Wang Q. MicroRNA-802 plays a tumour suppressive role in tongue squamous cell carcinoma through directly targeting MAP2K4. Cell Prolif. 2017;50:3. doi:10.1111/ cpr. 12368

15. Karatas OF, Oner M, Abay A, Diyapoglu A. MicroRNAs in human tongue squamous cell carcinoma: from pathogenesis to therapeutic implications. Oral Oncol. 2017;67:124-130. doi:10.1016/j.oraloncology.2017.02.015 
16. Zhou W, Zhang C, Jiang H, Zhang Z, Xie L, He X. MiR-493 suppresses the proliferation and invasion of gastric cancer cells by targeting RhoC. Iran J Basic Med Sci. 2015;18(10):1027-1033.

17. Cui A, Jin Z, Gao Z, et al. Downregulation of miR-493 promoted melanoma proliferation by suppressing IRS4 expression. Tumour Biol. 2017;39(5):1010428317701640. doi:10.1177/1010428317701640

18. Xu Y, Ge K, Lu J, Huang J, Wei W, Huang Q. MicroRNA-493 suppresses hepatocellular carcinoma tumorigenesis through downregulation of anthrax toxin receptor 1 (ANTXR1) and R-Spondin 2 (RSPO2). Biomed Pharmacother. 2017;93:334-343. doi:10.1016/j. biopha.2017.06.047

19. Zhi D, Zhao X, Dong M, Yan C. miR-493 inhibits proliferation and invasion in pancreatic cancer cells and inversely regulated hERG1 expression. Oncol Lett. 2017;14(6):7398-7404. doi:10.3892/o1.2017. 7178

20. Livak KJ, Schmittgen TD. Analysis of relative gene expression data using real-time quantitative PCR and the 2(-Delta Delta C(T)) Method. Methods. 2001;25(4):402-408. doi:10.1006/meth.2001.1262

21. Zhao XP, Zhang H, Jiao JY, Tang DX, Wu YL, Pan CB. Overexpression of HMGA2 promotes tongue cancer metastasis through EMT pathway. J Transl Med. 2016;14:26. doi:10.1186/ s12967-016-0867-z

22. Zhang $\mathrm{H}$, Tang $\mathrm{Z}$, Deng $\mathrm{C}$, et al. HMGA2 is associated with the aggressiveness of tongue squamous cell carcinoma. Oral Dis 2017;23(2):255-264. doi:10.1111/odi.12608

23. Ren W, Wang X, Gao L, et al. MiR-21 modulates chemosensitivity of tongue squamous cell carcinoma cells to cisplatin by targeting PDCD4. Mol Cell Biochem. 2014;390(1-2):253-262. doi:10.1007/ s11010-014-1976-8

24. Jia LF, Wei SB, Mitchelson K, et al. miR-34a inhibits migration and invasion of tongue squamous cell carcinoma via targeting MMP9 and MMP14. PLoS One. 2014;9(9):e108435. doi:10.1371/journal.pone. 0108435
25. Peng F, Zhang H, Du Y, Tan P. miR-23a promotes cisplatin chemoresistance and protects against cisplatin-induced apoptosis in tongue squamous cell carcinoma cells through Twist. Oncol Rep. 2015;33 (2):942-950. doi:10.3892/or.2014.3664

26. Li J, Meng S, Xu M, et al. Downregulation of N(6)-methyladenosine binding YTHDF2 protein mediated by miR-493-3p suppresses prostate cancer by elevating N(6)-methyladenosine levels. Oncotarget. 2018;9(3):3752-3764. doi:10.18632/oncotarget.23365

27. Ueno K, Hirata H, Majid S, et al. Tumor suppressor microRNA-493 decreases cell motility and migration ability in human bladder cancer cells by downregulating RhoC and FZD4. Mol Cancer Ther. 2012;11 (1):244-253. doi:10.1158/1535-7163.MCT-11-0592

28. Gu Y, Cheng Y, Song Y, et al. MicroRNA-493 suppresses tumor growth, invasion and metastasis of lung cancer by regulating E2F1. PLoS One. 2014;9(8):e102602. doi:10.1371/journal.pone.0102602

29. Kleemann M, Schneider H, Unger K, et al. Induction of apoptosis in ovarian cancer cells by miR-493-3p directly targeting AKT2, STK38L, HMGA2, ETS1 and E2F5. Cell Mol Life Sci. 2019;76 (3):539-559. doi:10.1007/s00018-018-2958-x

30. Wang X, Liu X, Li AY, et al. Overexpression of HMGA2 promotes metastasis and impacts survival of colorectal cancers. Clin Cancer Res. 2011;17(8):2570-2580. doi:10.1158/1078-0432.CCR-10-2542

31. Yang GL, Zhang LH, Bo JJ, et al. Overexpression of HMGA2 in bladder cancer and its association with clinicopathologic features and prognosis HMGA2 as a prognostic marker of bladder cancer. Eur $J$ Surg Oncol. 2011;37(3):265-271. doi:10.1016/j.ejso.2011.01.004

32. Zhu J, Wang H, Xu S, Hao Y. Clinicopathological and prognostic significance of HMGA2 overexpression in gastric cancer: a metaanalysis. Oncotarget. 2017;8(59):100478-100489. doi:10.18632/ oncotarget.19001

33. Zhuo HC, Song YF, Ye J, Lai GX, Liu DL. MicroRNA-154 functions as a tumor suppressor and directly targets HMGA2 in human non-small cell lung cancer. Genet Mol Res. 2016;15:2. doi:10.4238/gmr.15028173
OncoTargets and Therapy

\section{Publish your work in this journal}

OncoTargets and Therapy is an international, peer-reviewed, open access journal focusing on the pathological basis of all cancers, potential targets for therapy and treatment protocols employed to improve the management of cancer patients. The journal also focuses on the impact of management programs and new therapeutic

Submit your manuscript here: https://www.dovepress.com/oncotargets-and-therapy-journal agents and protocols on patient perspectives such as quality of life, adherence and satisfaction. The manuscript management system is completely online and includes a very quick and fair peer-review system, which is all easy to use. Visit http://www.dovepress.com/ testimonials.php to read real quotes from published authors. 